\title{
EDITORIAL
}

\section{Initial immunosuppression and managing rejection}

\author{
Thomas Fuehner ${ }^{1,3,4^{*}}$, Christian Benden ${ }^{2}$ and Jens Gottlieb ${ }^{1,3}$
}

(c) 2019 Springer-Verlag GmbH Germany, part of Springer Nature

\section{Introduction}

Since the beginning, long-term patient and graft survival have improved significantly for all sorts of solid organ transplantation. A major step in prolonged graft survival was the improvement of graft tolerance by advances in immunosuppression preventing acute graft rejection, and progress in surgical technique, particularly in thoracic transplantation. Even with modern immunosuppressive protocols, acute graft rejection and chronic allograft dysfunction are still of concern. Long-term immunosuppressive therapy is accompanied by side effects and toxicity. A multidrug approach allows one to lower target doses of each medication, helping to reduce toxicity of early and maintenance immunosuppression [1].

Immunosuppressive agents can be categorized as induction therapy and maintenance treatment. The treatment goal is prevention of graft rejection and tolerance induction. Induction allows one to withhold high doses of conventional immunosuppression, consisting of parenteral drugs. Maintenance immunosuppression is usually given orally as a lifelong treatment. Early immunosuppressive regimens included high-dose corticosteroids and azathioprine. Further improvements were achieved in the 1980s by the addition of calcineurin inhibitors to these regiments, improving graft survival dramatically. In the modern era, individualization of immunosuppressive regimes is possible by introduction of new agents, e.g., proliferation signal inhibitors and co-stimulation blockade.
*Correspondence: fuehner.thomas@mh-hannover.de

1 Department of Respiratory Medicine, Hannover Medical School, 30623 Hannover, Germany

Full author information is available at the end of the article

\section{Transplant immunology}

It is important to understand the basic immunology in solid organ transplantation tolerance by action of immunosuppressive agents. MHC (major histocompatibility complex) molecules are located on the surface of donor cells and are the leading target of the immune response to the graft. The adaptive immune response against the donor graft starts with the recognition of an alloantigen by a naive $\mathrm{T}$ cell. The $\mathrm{T}$ cell subsequently proliferates and differentiates [2]. This primary event requires the interaction of the $\mathrm{T}$ cell receptor (TCR) with antigen presented as a peptide by the antigen-presenting cell (APC) and a co-stimulatory receptor/ligand interaction on the T cell/ APC cell surface. Activated T cells have cytotoxic properties, may interact with B cell antibody production, and induce macrophage hypersensitivity response. Activation of $\mathrm{T}$ cells and proliferation is described by the three-signal model [3]. Signal 1 is when an APC binds to the TCR and triggers the $T$ cell. Signal 2 is when co-stimulator molecules and ligands bind. The activation of both signals 1 and 2 is needed to result in the expression of cytokines, e.g., interleukin-2 (IL-2). Signal 3 is when stimulation of the IL-2 receptor on the T cell surface triggers $\mathrm{T}$ cell proliferation. Immunosuppressive agents may affect (1) the cytokine release/production of activated T cells, (2) the T cell proliferation, (3) downregulate/inhibit TCR, or (4) cause $\mathrm{T}$ cell depletion [3]. The major targets of immunosuppressive therapy are displayed in Fig. 1.

\section{Induction therapy}

Induction immunosuppressive therapy is administered immediately at transplantation, aiming for an acute and intense immunosuppressive effect that allows delayed and gradual introduction of conventional immunosuppression. Induction therapy is not universally used in solid organ transplantation. According to large US registries, use of induction therapy is lowest in liver transplant

\section{Springer}




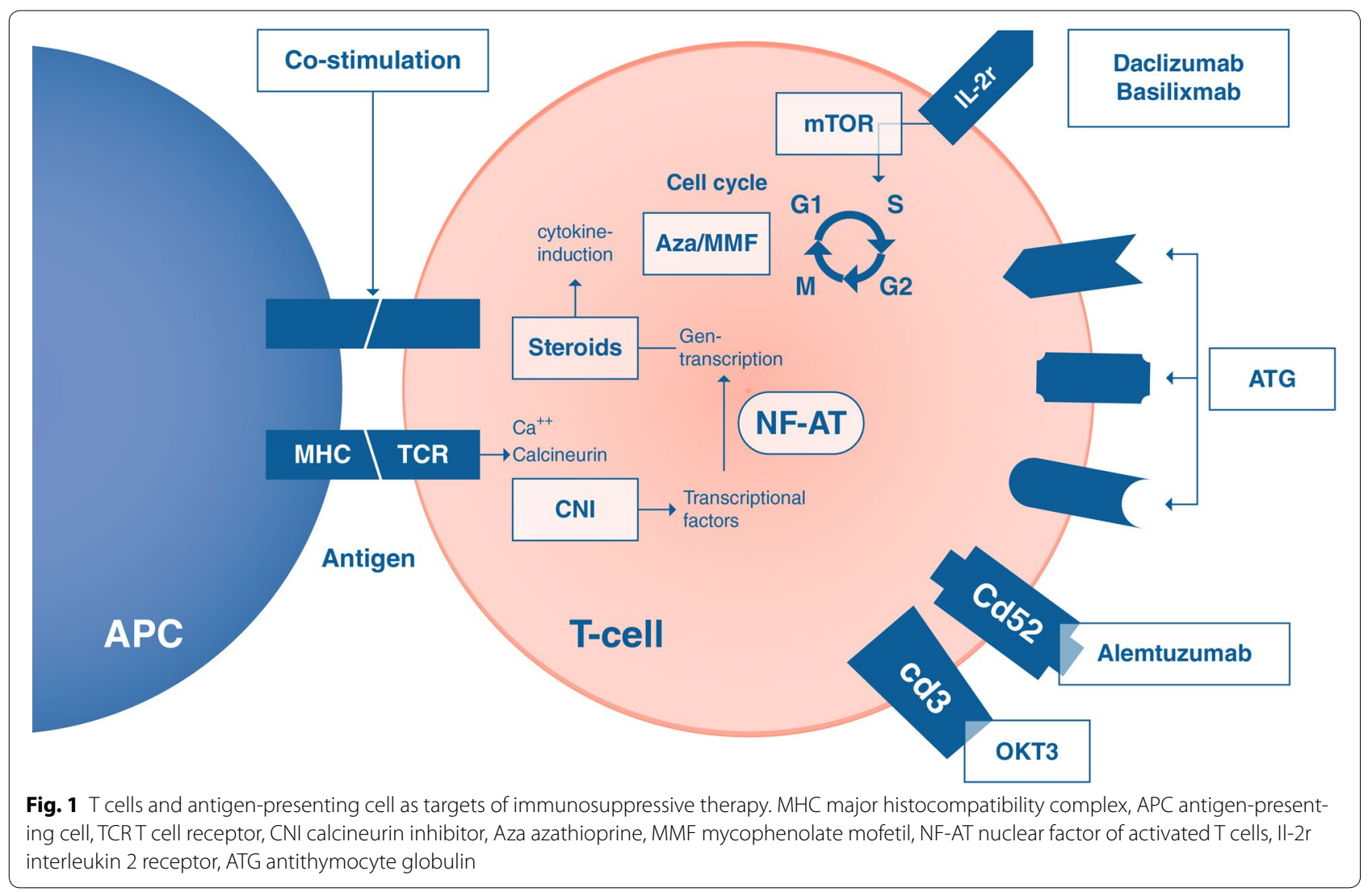

recipients (31\%) and highest in pancreas recipients (90\%) [4]. Induction therapy includes $\mathrm{T}$ cell-depleting and non-depleting agents, depleting antibodies divided into polyclonal and monoclonal agents. Antithymocyte globulins contain polyclonal antithymocyte antibodies. Alemtuzumab, a newer induction agent, is a humanized monoclonal anti-CD52 antibody, leading to profound $\mathrm{T}$ cell depletion. There are two non-depleting antibodies used in solid organ transplantation for induction therapy, daclizumab and basiliximab, both anti-IL-2 receptor antagonists. Protocols without classic induction therapy consist of a 3-day course of high-dose intravenous methyl prednisolone and higher doses of typical maintenance medications [5]. In addition, $\mathrm{T}$ cell-depleting agents can also be used for the treatment of acute cellular graft rejection $[6,7]$.

\section{Maintenance therapies}

Calcineurin inhibitors (cyclosporine and tacrolimus) are cornerstones of the immunosuppressive strategy, used combined with cell cycle inhibitors, corticosteroids, mammalian target of rapamycin (mTOR) inhibitors, and $\mathrm{T}$ cell co-stimulation blockers [1, 3]. Usually recipients are treated with either a two- or three-drug regimen. A triple maintenance drug regime is the preferred mode of most centers' protocols from the beginning (58-84\%), followed by different withdrawal strategies in practice (SRTR registry data) [8].

While intubated, patients receive immunosuppressants via a nasogastric tube or by parenteral administration. Intravenous administration of calcineurin inhibitor is critical; however, as there is no universally recommended regimen, most centers use prolonged infusion. Drug monitoring via blood samples drawn from lines used for calcineurin inhibitor infusion is not recommended because of sampling errors as the drugs adhere to plastic coatings. The calcineurin inhibitor dose is adjusted on the basis of therapeutic drug monitoring by trough levels. Diarrhea or gastroparesis may affect resorption [9]. The intravenous dose of calcineurin inhibitor is approximately one-third of the enteral dose. Most immunosuppressants can be administered enterally, which is the preferred route. Proliferation signal inhibitors are usually not initiated early post-transplant in the intensive care unit because of impaired wound healing early after surgery, which is particularly problematic for bronchial anastomotic healing post lung transplantation [10]. 


\section{Rejection therapy}

Acute rejection is subcategorized into acute cellular rejection (ACR) and antibody-mediated rejection (AMR). The latter form is caused by alloantibodies directed against donor-specific anti-HLA antigens. These antibodies may pre-exist before transplantation or develop de novo following transplantation. Also, non-HLA may play a role. Within the first postoperative year, ACR is particularly common after lung, liver, and heart transplantation. Acute cellular rejection is mediated by $\mathrm{T}$ lymphocyte recognition of foreign $\mathrm{MHC}$ [11]. In kidney transplantation, AMR is the most frequent cause of late allograft failure [11]. Donor-specific antibodies (DSAs) can cause detrimental effects in the allograft following its detection in blood. However, DSAs may also just be a transient phenomenon, disappearing without specific treatment. The diagnosis of AMR usually requires three components: graft dysfunction, histologic evidence of allograft injury, and circulating DSAs. DSAs are nowadays usually detected by solid-phase assays (e.g., Luminex ${ }^{\circledR}$ ) which are highly sensitive but may afford false positives. High-dose glucocorticoids are usually first-line therapy for moderate to severe ACR [12]. The optimal treatment for acute AMR is unknown. Usually, a combination therapy aiming to deplete circulating antibodies and suppress B cells is initiated, but it is not always successful. Most protocols contain plasma exchange, intravenous immunoglobulin, and application of rituximab $[6,7]$.

\section{Future strategies in immunosuppression}

Novel strategies in immunosuppression include nanoparticle-based approaches which modulate the alloimmune response by delivering these small compounds to APCs in vivo. New agents such as recombinant growth factor which affects the differentiation of dendritic cell progenitors and regulatory $\mathrm{T}$ cell therapies may improve immune tolerance $[13,14]$. New technologies (e.g., genomewide scans and haplotype analysis) screening the entire genome to recognize determinants of drug responses may allow a personalized treatment approach and avoid toxicities [15].

\footnotetext{
Author details

${ }^{1}$ Department of Respiratory Medicine, Hannover Medical School, 30623 Hannover, Germany. ${ }^{2}$ Division of Pulmonology, University Hospital Zurich, Zurich, Switzerland. ${ }^{3}$ Biomedical Research in Endstage and Obstructive Lung Disease Hannover (BREATH), Member of the German Center for Lung Research (DZL), Hannover, Germany. ${ }^{4}$ Department of Respiratory Medicine, Städtisches Klinikum Braunschweig, Brunswick, Germany.
}

\section{Compliance with ethical standards}

Conflicts of interest

The authors have no conflicts of interest in respect to this article.

\section{Ethical approval}

An approval by an ethics committee was not applicable.

\section{Publisher's Note}

Springer Nature remains neutral with regard to jurisdictional claims in published maps and institutional affiliations.

Received: 2 November 2018 Accepted: 24 December 2018

Published online: 15 March 2019

\section{References}

1. Wiesner RH, Fung JJ (2011) Present state of immunosuppressive therapy in liver transplant recipients. Liver Transpl. 17(suppl 3):1-9

2. Murphy K, Travers P, Walport M (2008) Immunobiology, 7th edn. Garland Science, New York

3. Halloran PF (2004) Immunosuppressive drugs for kidney transplantation. N Engl J Med. 351(26):2715-2729

4. Organ Procurement and Transplantation Network (OPTN) and Scientific Registry of Transplant Recipients (SRTR) (2014) 2012 OPTN/SRTR annual data report. HHS, Health Resources and Services Administration, Rockville

5. Post DJ, Douglas DD, Mulligan DC (2005) Immunosuppression in liver transplantation. Liver Transplant 11(11):1307-1314

6. van den Hoogen MW, Hesselink DA, van Son WJ, Weimar W, Hilbrands LB (2013) Treatment of steroid-resistant acute renal allograft rejection with alemtuzumab. Am J Transplant 13(1):192-196

7. Thymoglobulin [package insert] (2008) Genzyme Corporation, Cambridge

8. Table 1.9b: immunosuppression use by organ maintenance regimen at discharge, 2011 transplants. Scientific Registry of Transplant Recipients website. http://www.srtr.org/annual_Reports/2011/109b_dh.aspx. Accessed 2 Oct 2014

9. Schuurmans MM, Tini GM, Zuercher A, Hofer M, Benden C, Boehler A (2012) Practical approach to emergencies in lung transplant recipients: how we do it. Respiration 84(2):163-175

10. Groetzner J, Kur F, Spelsberg F, Behr J, Frey L, Bittmann I, Vogeser M, Ueberfuhr P, Meiser B, Hatz R, Reichart B, Munich Lung Transplant Group (2004) Airway anastomosis complications in de novo lung transplantation with sirolimus-based immunosuppression. J Heart Lung Transplant. 23(5):632-638

11. Hart A, Smith JM, Skeans MA, OPTN/SRTR 2015 et al (2015) Annual data report: kidney. Am J Transplant 17(Suppl 1):21-116

12. Scheinman Rl, Cogswell PC, Lofquist AK, Baldwin AS Jr (1995) Role of transcriptional activation of I kappa B alpha in mediation of immunosuppression by glucocorticoids. Science 270:283-286

13. Zhang Y, Zhang G, Liu Y, Chen R, Zhao D, McAlister V, Mele T, Liu K, Zheng X (2018) GDF15 regulates Malat-1 circular RNA and inactivates NFKB signaling leading to immune tolerogenic DCs for preventing alloimmune rejection in heart transplantation. Front Immunol. 9:2407. https://doi. org/10.3389/fimmu.2018.02407

14. Boardman DA, Philippeos C, Fruhwirth GO, Ibrahim MA, Hannen RF, Cooper D, Marelli-Berg FM, Watt FM, Lechler RI, Maher J, Smyth LA, Lombardi G (2017) Expression of a chimeric antigen receptor specific for donor HLA class I enhances the potency of human regulatory T cells in preventing human skin transplant rejection. Am J Transplant 17(4):931943. https://doi.org/10.1111/ajt.14185

15. Zaza G, Granata S, Tomei P, Dalla Gassa A, Lupo A (2015) Personalization of the immunosuppressive treatment in renal transplant recipients: the great challenge in "omics" medicine. Int J Mol Sci. 16(2):4281-4305 